\title{
Section II: Poster Sessions
}

\section{ADOLESCENT \& CHILD HEALTH}

\section{P1-01 The Prevalence of Overweight and its Risk Factors among Adolescents in an Urban City in a Developing Nation}

Vivian O. Omuemu; Casimir E. Omuemu (University of Benin Teaching Hospital) Introduction: The prevalence of overweight is rising even in countries with significant rates of under-nutrition. This is exacerbated by Westernization of lifestyles and the image of prosperity associated with overweight. Children are not spared and the health consequences may become apparent in the near future. This study assessed the prevalence of overweight among adolescents in an urban city in a developing country.

Methodology: This cross-sectional study conducted from January to June 2006 involved 300 adolescents selected by cluster sampling in Benin-City, Nigeria. Overweight and risk of overweight were defined as Body mass index (BMI)-forage $>95$ th percentile and BMI-for-age 85 th to $<95$ th percentile respectively.

Results: Of the participants, $5.7 \%$ were overweight while $52.7 \%$ were at risk of overweight. Risk factors of overweight identified were consumption of snacks $(64.3 \%)$, soft drinks $(85.7 \%)$ and physical inactivity $(69.7 \%)$. Being overweight was significantly associated with consumption of snacks, soft drinks and physical inactivity, $(\mathrm{p}<0.05)$.

Conclusion: The high prevalence of risk factors for overweight suggests that the already high prevalence of overweight will increase in the near future. Preventive measures need to be put in place to forestall this projected increase.

\section{P1-02 Adolescent Aggression in Violence Entrenched Urban Environments: The Protective Role of Parenting}

Kantahyanee W. Murray; Denise L. Haynie (National Institute of Child Health and Human Development)

This study examines the relations between parenting and adolescent aggression among urban African-American youth exposed to high levels of community and school violence. A total of 254 U.S. inner-city public middle school students (males = 134; females $=120$ ) completed questionnaires at two time points about their aggressive behaviors and perceptions of parent support, monitoring, psychological control and disapproval of aggression. Correlation analyses revealed that Time 1 perceptions of parent disapproval of aggression is negatively associated with time 2 overt aggression. Further, Time 1 overt aggression is negatively associated with Time 2 perceptions of parent support, monitoring, and disapproval of aggression and positively associated with Time 2 psychological control. These findings suggest that parents may both influence the expression of aggression and respond to aggression by changing parenting strategies. Additional analyses will investigate the multivariate relations between Time 1 parenting and Time 2 aggression. It is expected that the multivariate results will reveal that a particular combination of parenting strategies foster adolescent resiliency against high levels of aggression involvement. 
This study will elucidate the protective role of parenting in preventing and mitigating adolescent aggression in violence entrenched urban environments.

\section{P1-03 Physical and Psychosocial Well-Being of Orphans and Vulnerable Children in the Face of Hiv/Aids: What are the Main Areas of Intervention in the Informal Settlements of Nairobi, Kenya?}

Penny Holding; Elizabeth Kahurani; Jean Christophe Fostso (AFRICAN POPULATION HEALTH RESEARCH CENTRE)

Physical and psychosocial well-being of orphans and vulnerable children in the face of HIV/AIDS: What are the main areas of intervention in the informal settlements of Nairobi, Kenya?

By the end of 1999, 13.2 million children had been orphaned worldwide by AIDS and $90 \%$ of them were in Africa (UNAIDS/WHO, 2000). From the increasing body of evidence being collected in Sub-Saharan Africa it is apparent that the types of support that should be considered to meet the needs of these children should go beyond purely material issues (Atwine 2005).

An OVC project carried out in 2006/7 in the informal settlements of Nairobi, Kenya elicited detailed information on the physical and psychosocial well being of OVCs and their caregivers. The specific objectives of the project were to:

1) Through regression analysis identify the relationship between child and family level factors and child welfare indicators, including psycho-social well-being.

2) Identify welfare concerns for OVCs in informal urban settlements.

3) Apply a reliable and valid method of proxy means testing (PMT) to identify households that would qualify for interventions based on their income or other related socio-economic status indicator.

Findings will further be explained by data that is currently being analyzed.

\section{P1-04 East Baltimore Male Youth have Limited Health Care Resources \& Significant Barriers to Care}

David K. Popiel MD, MPH; Arik V. Marcell MD, MPH; Freya Sonenstein PhD (Johns Hopkins Bloomberg School of Public Health)

Background: Male youth (ages 12-34) living in East Baltimore are exposed to frequent violence, drug use, and high-risk sexual activity. Little is known about this population's health care resources and barriers to care.

Objective: To characterize the need for and delivery of primary medical and reproductive care to male youth of East Baltimore.

Methods: A needs assessment was completed based on public data from the CDC, the Maryland Department of Health \& Mental Hygiene, and the Baltimore City Health Department. Resource mapping and semi-structured interviews of local health care providers were subsequently performed.

Findings: East Baltimore communities are identified as core neighborhoods for high incidence of STIs, adolescent childbearing, juvenile violent deaths, and percentage of families living in poverty. Few medical resources are identified that serve the local male population. Local health care providers identify factors that further explain the barriers to care for this population, including the lack of a perceived need for services and the lack of a male-friendly environment. Secondary to differential data tracking by the health care providers, comparable health care utilization data across settings is not possible at this time. 
Implication: The demonstrated need for primary care and reproductive health services for East Baltimore male youth demands consideration for expansion of current services and creation of additional resources.

\section{P1-05 Urban Children with Asthma PCP Visits Frequency and Activity Limitation}

Cassia Lewis-Land, MLA, CCRP; Jennifer Walker, MHS; Arlene Butz, ScD, RN, CPNP (Johns Hopkins University School of Medicine, General Pediatrics Division) Introduction: National guidelines suggest Primary Care Provider (PCP) follow-up visits at 1 to 6 month intervals for asthma control. Under utilization of PCP care by urban caregivers of children with asthma have been reported.

Methods: 231 caregivers of children 5-12 yrs with persistent asthma were asked about frequency of PCP visits and child $s$ activity restriction to assess association between PCP visits and caregivers perception of asthma control over 6 mos. Number of PCP visits were categorized into ?1 and ?2.

Results: Children were primarily male (63\%), African American (94\%), on Medicaid $(82 \%)$. Almost half $(42 \%)$ reported ? 1 vst $/ 6$ mos. Increased limitation of child $s$ activity was associated with children having ?2 PCP visits over 6 months (X 2= 5.9, $\mathrm{p}=0.04$ ) versus those with ? 1 . Number of PCP visits was not associated with daytime symptoms (?1 PCP visit: 5.6 days (SD 7.8) versus ?2 PCP visits: 6.6 days (SD 8.3 ); $\mathrm{p}=0.33$ ), or nighttime symptoms (?1 PCP visits: 5.0 nights (SD 9.3) versus ? 2 PCP visits: 5.0 (SD7.4) nights; $\mathrm{p}=0.99$ ).

Conclusion: Almost half of this group of urban children had inadequate PCP visits for appropriate asthma care. Increased PCP visits were associated with report of higher activity limitation.

\section{P1-06 Factors Influencing Sexual Behavior amongst Secondary School Students}

Ijeoma Amaeshi (Critical peers Nigeria, Oyo State Nigeria)

Objectives- To study the factors affecting sexual behavior of students in senior secondary students in Igbo-ora Oyo state

Issues- Youth sexual behavior predisposes them to STIs and HIV, evaluating the factors which influence their sexual choices enhances youth friendly interventions. Peer pressure single most important factor influencing decisions made by young persons

Description- A cross-sectional descriptive study to determine the factors influencing sexual behavior of senior secondary students in Igbo-ora, a multi stage random sampling of 6 secondary schools in Igbo ora

Lessons learnt-Poor knowledge about sexuality and peer pressure have a great influence on the sexual behavior of senior secondary school students' socioeconomic and cultural background does not play significant role

Recommendation-Establishment of youth friendly centers in close proximity to Secondary schools and parents should be the first source of sexual education. The government and NGOs should be encouraged in creating youth friendly policies and programme.

\section{P1-07 A Comparative Analysis of the Knowledge and Attitudes of School Students Belonging to Different Streams Regarding Various Aspects of Female Feticide and to Study How Health Education Influences this Knowledge and Attitude}

Surabhi Batra; Akshat Katyayan; Swati Gupta; Jugal Kishore (Maulana Azad Medical College)

In many parts of the world particularly in the India, female infanticides have degraded the integrity and status of women since ancient ages, but ever since the 
introduction of ultrasonographic equipment to determine the sex of the unborn child, introduced in India in 1979, a relatively new form of abuse against women has risen-that of FEMALE FETICIDE. This study has ventures to find out about the KAP (Knowledge Attitude and Practice) in the population that matters the most-the youth who are the future parents and thus more amenable to intervention.

Objectives: 1)To compare the difference in knowledge amongst the school students belonging to different streams, about female feticide and its various dimensions. 2)To analyze how health education changes the attitude of different groups of students about female feticide and its consequences.

Methodology: The study sample consisted of 300 students belonging to the age group of 15-20 years. Each student was made to fill out a questionnaire. For the purpose of analysis, the study group was divided into 2 sub-groups: school children in the science stream and school children in the non science stream. After the initial test these students were provided health education material and a few lectures. They were then given another test with the same questionnaire one week later and the results compared. The data was analyzed using Epi-info software.

Results: A very peculiar result was that not only the knowledge of the students differed their attitudes and beliefs about the subjects also varied directly with the amount of knowledge they had. After providing both the groups with health education though the health education material, the knowledge of both the groups became comparable. With this not only the knowledge but the attitudes of the students also changed.

Conclusion: Health education can serve as a very important measure to control the dwindling sex ratio in various countries where female feticide is getting rampant.

\section{P1-08 Computerized Medical Passport for Foster Kids Using Medicaid Data}

Deena J. Chisolm, PhD; Philip V. Scribano, DO, MSCE; Tanjala S. Purnell, MPH; Kelly J. Kelleher, MD, MPH (Columbus Children's Hospital)

Research Objective: Foster children face poor health care continuity. Disruptions in continuity lead to fragmentation of care, resulting in suboptimal health. This study explores the use of Medicaid claims data to create a personal health record to help achieve continuity of care.

Methodology: Information from Ohio Medicaid and Franklin County Child Protective Services (CPS) was used for this study. A database including all care for the sampled children, across all historical Medicaid numbers, was created by Ohio Medicaid. Utilization data for the study youth were used to create sample personal health records.

Principal Findings: Success of this pilot was measured using three criteria: 1) completeness of matching individuals identified by CPS with records in Medicaid data; 2) quality of provider information; and 3) quality of clinical information. The process was successful in matching foster youth using identifiers in the CPS system to claims in the Medicaid system. Limitations were seen in the second and third criteria.

Conclusions: Based on the defined criteria, this study can be considered a success with notable limitations. Despite these limitations, the pilot demonstrates that Medicaid data can serve as an excellent starting point for patient-level personal health records for youth in foster care systems. 


\section{BEST PRACTICES IN MEETING URBAN HEALTH CHALLENGES}

\section{P2-01 Journey to Connectedness - Innovative Approaches to Addressing Health and Homelessness in Canada}

Valine Vaillancourt, RN, BScN, BA, MEd; Niki Gately, BA, MEd (candidate) (Mental Health/Outreach Team, Public Health Services)

In recent years our community has banded together in response to the complex matrix of health and social issues faced by individuals experiencing homelessness. Many of these innovations were initiated using existing human and financial resources. Since the Community Action Plan on Homelessness in 2000, many exciting new programs have been developed through the creative and innovative collaboration of individuals committed to addressing homelessness in meaningful ways. Some are described below:

The Hospitals-Shelters Working Group - addressing complex discharges of homeless individuals, development of a resource toolkit and an interdisciplinary education program.

The Shelter Health Network - health professionals, social service organizations, programs and funding sources collaborating to provide primary healthcare in shelters. The collaboration is connected through agreements and shared planning rather than four walls and a common funding source. When people's lives have stabilized, we make referrals to community family physicians. Our close link with McMaster University means that our network can help other health providers understand the problems of health and homelessness.

Other community groups involved in this innovative collaboration are: Street Outreach Coalition, Hostels to Homes (Pilot) Project, Salvation Army Discharge Beds Program, Claremont House Special Care Unit (Management of Alcohol), and the new Crisis Beds Program.

\section{P2-02 Client and Staff Satisfaction with Technology-Based Data Collection in an HIV Testing Setting}

Dale R. Gluth, MA; Shelley N. Facente, MPH (Magnet)

Issues: In 2006, Magnet launched a system that enabled HIV testing clients to selfadminister a survey on a handheld computer prior to testing, eliminating test counselor paperwork. Despite initial skepticism about feasibility and effectiveness, the results were outstanding and most fears of the switch to technology were unsubstantiated.

Description: $89.1 \%$ of clients utilizing the new system claimed it was very easy to use, $54.6 \%$ of clients responded they were more likely to return to the site using this system as a result, and $89.9 \%$ claimed that the survey length was just right, remarkable given the volume of required questions $(\mathrm{n}=1069)$. Counselors also reported increased satisfaction. Fears of theft, client inability to use the handhelds, or language barriers proved unfounded.

Lessons Learned: It is both feasible and effective to collect risk and demographic data directly from clients using an electronic, self-administered format. Doing so improves client and counselor satisfaction with the experience, increases program efficiency, and improves data quality.

Recommendations: PalmIT collects data directly from clients, appends electronic laboratory and program information, and exports to the State data system. Its simple design is a model for any technology-based data collection system intended to reduce paperwork burden and improve client services. 


\section{P2-03 Promoting Health Through Community Collaboration}

Robin Foster-Drain, MD, MPH; Stephanie Medley (To Our Children's Future With Health)

Youths living in inner-city communities, of low socio-economic status (SES), have a greater risk of developing diseases and conditions, such as diabetes, asthma, and obesity, that require increased medical attention. The American Academy of Pediatrics (AAP) recommends that school age children receive a medical examination almost every year. Although it is essential that all children, especially low SES children, receive yearly physicals, many children are not getting this due to disparities in access to primary health care and a lack of regulations that ensure timely access to care. To Our Children's Future With Health, Inc., through its Promoting Health through Community Collaboration (PHCC) component, has developed a way to bridge the gap between the parent and the health care provider in order to ensure that all children receive an annual physical as recommended by the AAP. TOCFWH mandates that all youth, in its after-school programs, must have a current physical on file, in order for the youth to attend the program. PHCC will schedule physicals for youth who do not have physicals on file, and if a youth does not have a primary care physician, the youth can still receive a physical through one of the collaborating health care providers.

\section{NEIGHBORHOOD LEVEL INFLUENCES ON HEALTH}

\section{P3-01 Ethnic Disparities in Traffic Density and Transportation Benefits in the City of Boston, Massachusetts}

Rana Charafeddine (Centre de recherche La-Roback sur les ingalits sociales de sant de Montr)

Previous studies have shown that in California, low-income and minority groups are more likely to live in high traffic density neighborhoods. In this study, we investigate ethnic disparities in exposure to high traffic density and in the benefits accrued from the transportation system in the city of Boston. We relate exposure to high traffic density with few available measures of transportation benefits including vehicle use and short time of commute to work. Our findings suggest two patterns of ethnic disparities in Boston. The first pattern is that of people living in Asian neighborhoods who are substantially exposed to high traffic density, while having the lowest benefit from roadways in terms of private vehicle use. We discuss the equity implication of such pattern. The second pattern is that of residents of African American neighborhoods who have the lowest exposure to high traffic density but coupled with the longest time of commute to work. We speculate that this situation may be due to slow and inadequate public transit resources in African American neighborhoods. Future studies are needed to explore the health impacts of such ethnic disparities in the city of Boston.

\section{P3-02 Assessing and Meeting the Needs of Parents in Arlington County, VA}

Marina S. Moses, DrPH, MS, (Dept. of Environmental and Occupational Health, GWU SPHHS); Donna Caruso, RN, MS (Arlington County Schools); Tim Otten, MPH (GWU SPHHS); Tee Guidotti, MD MPH, (Dept of Environmental and Occupational Health, GWU SPHHS) (The George Washington University School of Public Health and Health Services)

A multi-level public health preparedness study was conducted on parents in Arlington County, Virginia with an emphasis on the Latino community in order to assess how best to convey public health information. Based on the findings of three focus groups, a community survey was administered to parents attending parent/teacher conferences in 
March of 2006. The survey was offered in English or Spanish and was used to evaluate differences that may exist between English and Spanish speakers regarding where and how to provide the cohort with public health information in addition to their levels of personal preparedness, access to preparedness materials, and personal needs. Univariate and multiple regression analyses were performed to characterize the sample population and predict personal preparedness. When parents were questioned if they would like to attend an information/training session on public health preparedness, 71\% of English respondents said they would attend and 100\% of Spanish responded reported they would attend. Both English and Spanish respondents stated they would prefer to attend sessions in school (96\% versus $93 \%$ respectively) rather than Community Centers $(71 \%$ versus $60 \%$ ) or places of worship $(42 \% ; 61 \%)$. The preferred sources for information acquisition varied between language groups. In descending order, English speakers prefer information from: Internet (68\%), Information Session (66\%), TV (63\%), Pamphlet (61\%), and Radio (55\%). In descending order, Spanish speakers prefer information from: TV (87\%), Information Session (83\%), Radio (75\%), Pamphlet $(67 \%)$, and Internet (28\%).Differences between groups, such as language and cultural barriers, lower literacy levels, and different preferences for acquiring information need to be considered in designing outreach programs for the Latino population. A model, called Community Ready! is being developed as the practical application of this knowledge to distribute information in other municipalities.

P3-03 Utility of Existing Systematic Social Observation Tools in Toronto Neighbourhoods. A. N. Scott; R. Nisenbaum; P. Balasubramaniam; A. Jabbar; S. Jacobs; T. Hason; J. Parsons; J. Ramsay; A. Ritchie; G. Singh; Q. Zaidi; P. O’Campo; J. Dunn. (The Centre for Research on Inner City Health, The Keenan Research Centre in the Li Ka Shing Knowledge Institute of St. Michael's Hospital, Toronto, Ontario, Canada.) Background: Neighbourhood characteristics contribute to residents' health and wellbeing. British and American studies have measured the health effects of neighbourhood characteristics using systematic social observations (SSO); however the utility of these tools in the Canadian context is unknown.

Methods: 176 block faces were randomly selected from two high and four low income neighbourhoods in Toronto, Canada. Four published SSO tools were amalgamated to create a 98 item instrument. A one-week, intensive training course ensured high inter-rater agreement. Dichotomous exploratory factor analysis was performed to determine if published constructs could be validated in the Toronto context.

Results: The median percent agreement calculated on a sample of 16 block faces was $89.3 \%$. $18 \%$ of questions had a prevalence of less than $5 \%$; these questions predominately dealt with social disorder. Exploratory factor analysis extracted a one-factor solution, Physical Decay and Disorder, made up of 7 items (median neighbourhood scores between 1-4) similar to a published US study. Constructs representing social disorder and territoriality could not be elicited from the data.

Summary: Existing SSO tools were not uniformly useful in Toronto neighbourhoods. Results obtained here will inform the development of a SSO tool applicable to the Toronto context.

\section{P3-04 The Effect of Black Tea on Blood Lipids and Fecal Fat}

Steva Komeh-Nkrumah, RD, LD, DrPH NCCAM Research Fellow (Morgan State University)

Cardiovascular disease (CVD) is the leading cause of death and disability in the United States. High cholesterol increases risk for CVD. Studies have shown that 
habitual tea-drinkers have reduced blood lipid levels and there-by reduced risk for CVD. This study compared the effect of black tea and two placebo beverages on fecal fat levels and blood lipid levels in humans.

Study Design: Study participants were 10 male smokers, ages 24 to 67, who volunteered for a feeding study at Beltsville Human Nutrition Research Center in Beltsville, Participants were randomly assigned to receive each treatment beverage in a crossover design, without repetition. The three treatment beverages were placebo with none of the phytonutrients in black tea $(\mathrm{P})$, placebo with caffeine in the amount present in black tea $(\mathrm{P}+\mathrm{C})$, and black tea $(\mathrm{T})$. Treatment periods were seven weeks long during which participants ate a controlled diet and consumed seven servings of study beverage per day.

In the seventh week of each study period blood was collected from participants. Participants also collected complete stool samples that were analyzed for fecal fat content, using CEM Fat Extraction System and methylene chloride solvent, to provide data for this research.

Findings: Seven servings of black tea per day reduced total cholesterol by $6 \%(\mathrm{p}=$ $0.03)$ and LDL-cholesterol by $9 \%(\mathrm{p}=0.02)$ compared with $\mathrm{P}$. There was no significant change in HDL-cholesterol. Mean fecal fat per week with black tea (23.4 gms.) showed a significant decrease $(\mathrm{p}=0.04)$ when the mean fecal fat per week was compared with $\mathrm{P}$ (38.9 gms).

Conclusion: Sustained consumption of black tea significantly reduced total cholesterol and LDL-cholesterol without reducing HDL-cholesterol.

\section{P3-05 Full Service: Talking about Fighting Prostate Cancer - In the Barber Shop!}

Mario C. Browne, MPH, CHES; Craig Fryer, DrPH; Sandra Quinn, PhD; Angela F. Ford, PhD; Stephen B. Thomas, PhD (University of Pittsburgh Graduate School of Public Health Center for Minority Health)

Objective: The purpose of this project is to promote prostate cancer screening, education about disease risk and the importance of early detection, and survivorship among African American males who frequent African American owned barber shops.

Strategy: In recognition of National Men's Health Week and Father's Day, the Center for Minority Health $(\mathrm{CMH})$ of the Graduate School of Public Health at the University of Pittsburgh partnered with the University of Pittsburgh's Cancer Institute (UPCI) and the American Cancer Society (ACS) to facilitate a day of prostate cancer awareness and screening in four African American owned barber shops in three predominantly African American neighborhoods. On two consecutive days, two separate teams, each consisting of an oncology fellow, public health professionals, an ACS representative and prostate cancer survivors, visited the barber shops to engage the customers in a conversation about prostate cancer screening and detection, diagnosis, and survivorship. Approximately 103 men received the most recent information about prostate cancer, screening guidelines, treatment options and side effects. Two of the shops offered awareness education only; another offered awareness education and onsite PSA blood testing, while the fourth offered PSA and DRE examinations by nurse practitioners from UPCI, in addition to education.

Our take home message: go to where the men are with the full-service, when possible.

\section{P3-06 Making a Difference: Voices from East Baltimore Childcare Providers} Jodi Shaefer, PhD, RN; Jennifer Wenzel, PhD, RN, CCM; Demetria Nichols, BS (Johns Hopkins University School of Nursing)

Successful childcare programs are critical to children's health and educational preparedness. The East Baltimore Educational Initiative's Early Childhood Working 
Group initiated a partnership with the Johns Hopkins School of Nursing to conduct community assessment sessions to provide data needed to design programs adequately addressing childcare providers' needs/wants. Topics included communication, transportation, trainings/activities, and cultural enrichment.

Thirty-two African American childcare providers attended a single 60-90 minute sessions. Providers portrayed themselves as having important and foundational relationships with children. They also identified themselves as mentors/support persons for parent(s), expressing a belief that they were able to counteract negative environmental/cultural influences on families. They consistently reported a commitment to making a difference in the lives of children, expressing a desire to enhance/ augment childcare services currently provided and a need to enlist community and family support for childcare in East Baltimore. Participants believe they need assistance/training with many facets of their work. Some of these areas include: teaching, mentoring, referral and resources for children with behavioral problems. These providers seek training to become better trainers for future generations of children and parents. Providers believe there are numerous existing opportunities for community partnerships with local resources but wish to see these expanded.

\section{SOCIAL DETERMINANTS OF HEALTH}

\section{P4-01 Determinants of Iron Deficiency Anemia among Teenage Antenatals-A Study in Southern India}

Korlagunta K. Sayi Prasad, MBBS, PhD; S. J. Kiranmayi, BSc, MS (Catholic Health Association of India (C.H.A.I))

Objectives: To examine the major determinants of iron deficiency anemia among teenage pregnant women attending an urban hospital run by The State Government.

Design: Case study approach

Subjects: 100 pregnant women and their controls attending antenatal out patient clinic in Andhra Pradesh

Setting: Government Maternity hospital, Tirupati,A.P

Results: Nearly $42 \%$ of the study population did not attain education beyond primary level and higher levels of education were associated with higher levels of red-cell hemoglobin ( $\mathrm{p}$ value 0.0000). Multiparity was a strong determinant of anemia ( $\mathrm{p}$ value 0.0423 ). Less number of clients with less than $8 \mathrm{gms} \mathrm{Hb}$ used iron and folic acid tablets ( $\mathrm{p}$ value 0.0297 ). History of previous fetal wastage did not appear to be a major determinant ( $\mathrm{p}$ value o.0111). Clients with $\mathrm{Hb}$ more than 8 gms used sanitary latrines significantly higher than the rest of the clients ( $p$ value 0.0101). Anemics with $\mathrm{Hb}$ less than 8 gms suffered from symptoms of hyperdynamic circulation than others in the study sample.

Conclusion: In conclusion, societal factors like education of the client, over work, repeat conception, cultural factors like food habits, environmental factors like open field defecation and bio-familial factors like health status of the women and parity of client - were some of the major determinants of 'anemia' among the antenatal respondents in this urban sample.

\section{P4-02 Negative Income Incongruity and Adverse Birth Outcomes}

\section{C. Messer; N. Dole; P. Mendola (U.S. EPA /NHEERL)}

We examined the effects of negative income incongruity (lower household income than tract median household income) on preterm birth (PTB $<37$ weeks completed gestation) 
using self-reported income for white and black women living in Wake County NC tracts (1995-2005). Geocoded pregnancy cohort $(n=1056)$ and U.S. census $(2000)$ data were analyzed in race-stratified logistic regression models. Income was collected during the 2nd trimester; gestational age was calculated from early ultrasound.

Blacks were less likely than whites to live in incongruous tracts (Odds Ratio $[\mathrm{OR}]=0.6$; 95\% Confidence Interval $[\mathrm{CI}]: 0.4,0.8)$. White women of low education $(</=12$ years $)$ were more likely to live in incongruous tracts $(\mathrm{OR}=1.8$; CI: $1.1,3.0)$ than less educated black women (OR: 1.3; CI: 0.9, 1.9). Being an older white women (30-34 and 35+) was protective against negative income incongruity $(\mathrm{OR}=$ 0.4 ; CI: $0.2,0.9$ and $\mathrm{OR}=0.4$; CI: $0.2,1.0$, respectively), as was being unmarried $(\mathrm{OR}=0.4$; CI: $0.2,0.7)$. In adjusted models, negative income incongruity was not associated with PTB for white women $(\mathrm{OR}=0.7$; CI: $0.3,1.6)$ but was suggestive of increased odds for black women $(\mathrm{OR}=1.5$; $\mathrm{CI}$ : $0.8,3.0)$.

Unlike previous research, this work finds little evidence for an association between reported income incongruity and PTB.

\section{P4-03 Black in America: From Commodities to Disparities, Race, Class and Public Health}

Melody S. Goodman, PhD; Jewel D. Stafford, MSW (Center for Public Health and Health Policy)

Racial disparities in health have been consistently observed in mortality, morbidity and other indicators of health on the state and national levels. From the colonization of the New World to present day, African-Americans have experienced higher rates of infectious and chronic diseases, are more likely to be diagnosed with later stages of diseases, and are less likely to receive the recommended levels of care. The constructs of race, class and public health have been greatly influenced by the legacy of slavery, racism and segregation. African-Americans continue to experience oppression, discrimination and injustices within their social environment. The impact of historical medical and scientific institutional practices on the African-American population has contributed to the social and behavioral risk factors for racial/ethnic health disparities. Despite these challenges, African Americans have developed social, political and economic infrastructures to empower and transform their communities. We will discuss how the tools of Community Based Participatory Research can transform the complex relationship of race, class and public health into collective action. We will examine the parallel social and behavioral risk factors that have historically impacted African American populations.

\section{P4-04 Racial Disparities in 4 Major Cancers and Socioeconomic Status in the District of Columbia}

Heather A. Young; Muhannad Hafi; Paul H. Levine; Susan S. Devesa; Grant Tao; John Davies-Cole (The George Washington University)

Cancer incidence data at the census tract level were obtained from the DC Cancer Registry for 1997-2001. Census tracts were divided into socioeconomic tertiles based on the percentage of individuals below the poverty line in 1999 as reported by the 2000 US Census. Age-adjusted cancer incidence rates and 95\% CI were calculated within each of the socioeconomic groupings. Rate ratios and $95 \%$ CI were calculated to compare black to white rates among the socioeconomic tertiles.

Black females had significantly lower rates of breast cancer than white females, and rates rose with decreasing poverty level. There was a trend of decreasing incidence of prostate cancer with increasing poverty level among black males. Black 
males and females had pronounced increases in rates of lung cancer with rising poverty levels. All four race/gender groups showed evidence of a trend of rising incidence of colon cancer with increasing poverty levels. In addition, black males and females had significantly higher rates of colon cancer than their white counterparts in the highest socioeconomic group.

Poverty was associated with decreasing rates of female breast cancer and increasing rates in lung and colon cancers, which might partially explain the racial disparities of the above four cancers in DC.

\section{P4-05 Isolation, Ignorance and Illiteracy: Social Determinants of Health}

Afshan Naseem (Fatima Jinnah Women University, Rawalpindi, Pakistan); Faiza Naseem (Government Degree College (Women), B-Block Satellite Town, Rawalpindi, Pakistan) and "Audil Rashid (Department of Environmental Sciences, University of Arid Agriculture,(Fatima Jinnah Women University, Rawalpindi, Pakistan)

Objectives: Many diseases have now gaining considerable recognition from public health issue in developing countries. However the responses to the diseases have been marked by lack of coordination and commitment.

Methods: The factors were determined focusing ruler population to know the detail information about spreading of diseases (1) people who are affected by diseases: their personal life, habits, living, liking and disliking and their status in community (2) modes that how they get infected (3) knowledge of people regarding mother-to-child transfer of virus, and (4) The rejoinder of community in reaction to affect from diseases in developing countries.

Results: The main causes found for infection from diseases in developing countries was isolation due to remoteness of the areas, ignorance and illiteracy. The poor education in developing countries is the prime cause that people are ignorant in relation to the spread of diseases. People, living in isolation especially in remote areas, are ignorant and they do not follow protective measures to avoid spreading diseases.

Conclusion: Our participation in research protocol will be valuable in order to minimize existing barriers to full adoption of effective measures to prevent spread of diseases in this Region.

P4-06 Social Determinants of Adolescent Unintended Pregnancy in the United States Jessica K. Levy (University of North Carolina- School of Public Health)

Despite its steady decline since the early 1990s, the United States pregnancy rate, among 15-19 year olds, remains a serious public health problem. In addition to its potentially wide-ranging, negative health and social consequences, the current U.S. adolescent pregnancy rate continues to be a concern because it is much higher than those of most other developed countries. Building on this information, this paper will explore why adolescent pregnancy still exists on such a large scale in the United States, especially in comparison to other developed nations. Population predictors which may differ from country to country will be examined. There will be a focus on significant social determinants, such as the intersection between societal attitudes around adolescent sexual activity and the provision of family planning education and services to teenagers. In an attempt to understand how distal predictors, such as societal attitudes, can influence the outcome of unintended pregnancy, Anthony Giddens' theory of structuration will be used. To conclude, suggestions for intervention will be provided. 


\section{P4-07 Perceived Knowledge of Partner'S Serostatus and Multiple Sex Partners: Preliminary Analysis of Heterosexuals at High Risk for HIV in DC}

K. D. Shelley; I. Kuo; M. Magnus; J. A. Peterson; A. L. Rawls; S. Jackson; L. Montanez; T. West; F. Hamilton; M. Sansone; A. E. Greenberg (The George Washington University, School of Public Health \& Health Services)

Background: Washington, DC has the highest rate of AIDS cases in the US.

Having multiple sex partners is an important HIV risk determinant.

Methods: 301 individuals were recruited from January-May 2007 for National HIV Behavioral Surveillance via respondent driven sampling in Washington, DC. All participants (ages 18-50) reported at least one sex partner of the opposite sex in the past year and completed structured surveys on sexual behaviors.

Results: The mean age was 37.9 (SD:10.1); 60\% were female; 94\% were African-American; 90\% self identified as heterosexual and had a mean of 6.3 (SD:22.7) partners in the past year. At last sexual encounter, $25.6 \%$ used condoms and $51 \%$ responded they knew their partner's HIV status.

However, $41.9 \%$ believed their last partner had sex with others during their sexual relationship and $44.2 \%$ reported having sex with others during the sexual relationship with their last partner. Among participants with $>1$ sex partner in the past year ( $\mathrm{n}=186)$, those with casual or exchange partners (vs. main) at last sex were less likely to know the HIV status of their partner $(24.7 \%$ vs. $58.4 \%, \mathrm{p}<.0001)$.

Discussion: Given the high prevalence of self-reported multiple, concurrent sexual partners, perceived knowledge of partner's serostatus may not be accurate.

\section{P4-08 Perception of the Professionals Involved in the Family Health Strategy, about Your Quality of Life}

Ana Guilhermina Reis; Fabio Miguel Sartori Cauduro; Fernando Rudem Brasil; Jose Roberto Rosa dos Santos; Lair da Silva Muniz; Luciana B. A. Schmidt; Lucianne Pontes S. Justo; Maria Solange Knuth Ortiz; Susana Cristina Nunes (Health of the employees of the Bank of the Brazil. School of Public Health)

Background: The purpose of this research was to delineate the life quality perception of the professionals involved in the Family Health Strategy (FHS) teams, in three cities in the state of Rio Grande do Sul, Brazil. This study has the objective to promote life quality, reducing the vulnerability and risks related to FHS determinations and conditions, which are for instance, lifestyle, work requirements, habitation, environment, education, leisure, essential goods and services access.

Methodology: The methodology used was the exploratory-descriptive with a quantitative approach. The life quality data was collected through a general measure instrument, validated in Brazil, which was developed by World Health Organization (WHO) researchers and named WHOQOL-brief. This instrument was self applied on the target population during the team meetings, totalizing 47 professionals investigated.

Conclusion: The results suggest the necessity of the care in health of the professionals involved in the Family Health Strategy, so that they have guaranteed your citizenship with quality of life and mental health, developing compromised actions with the healthful human development. We consider that our study it will be able consequently to contribute with reflections of the social politics in the scope of the Urban Health benefiting professionals and your patients. 
P4-09 Average Consumption of Vegetables and Fruits among Inhabitants of Belo Horioznte Metropolitan Area, Minas Gerais State, Brazil.

Vitor Passos, Claudia Di Lorenzo, Fernando A. Proietti, Cibele C. Cýsar, Maria Fernanda Lima e Costa \& Belo Horizonte Urban Health Observatory. (UFMG)

Background: Diary consumption of vegetables and fruits has been pointed as an important habit to prevent cardiovascular diseases. In Brazil, studies have observed changes in the life stile of people, mainly in the large cities. In 2003, a survey was conducted in the Belo Horizonte Metropolitan Area (BHMA) in order to know behaviors, use of Health Services and self-reported morbidity. Among the questions, the consumption of vegetables and fruits was asked and we evaluated this variable and its correlation with others.

Methodology: A random sample of houses in the BHMA was chosen. All the permanent dwellers were invited to participate and answered to a face-to-face questionnaire. The average consumption of vegetables and fruits was estimated in number of portion by day in the last 30 days. We run a Poisson model, adjusting to the correlation among their dwellers. The dependable variable was the average consumption that varies from 0 to 5 portions by day.

Results: We interviewed 13632 dwellers, 7940 (58.2 \%) were from Belo Horizonte city and $5692(41.8 \%)$ were from others cities of the BHMA. The average consumption of vegetables and fruits was 1.5 portions by day. Among the interviewed, $6286(46.1 \%)$ were male and $7346(53.9 \%)$ female. The average age was 40 years old. In the final model the significant variables were: sex, age, years of schooling, regular practice of exercises and frequency of cigarettes smoked.

Conclusion: People who consume more vegetables and fruits are on average women, have more years of schooling, are older and they have healthier health related behaviors, such as more regular exercising and less smoking.

P4-10 Ethnographically Informed Formative Assessment: Understanding HIV Risk Populations in an Urban City: The DC Example

James Peterson, Irene Kuo (The George Washington University School of Public Health and Health Services, Department of Epidemiology and Biostatistics, Washington, D.C) Rates of HIV/AIDS in Washington, DC are among the highest in the U.S. However, little documentation exists about the high risk populations, the behaviors that these populations are engaged in that place them at increased risk and the geographic impact of these issues. This presentation will illuminate findings from an ethnographically informed formative assessment of HIV among heterosexuals at high risk conducted in DC as part of the CDC funded National HIV Behavioral Surveillance (NHBS). Field observations in high risk neighborhoods, 8 focus groups and 12 key informant interviews were conducted between October-December 2006. Of the 48 focus group participants, all but two reported having previously been tested for HIV. Emergent themes included how, recent economic development has significantly impacted low income residents in the city, and the identification of adolescents and young adults and Latinos as emerging risk populations for HIV. These findings provide some of the only qualitative data on populations at high risk for HIV in DC. Further ethnographic research is needed to define the important networks and geographical implications of this knowledge. 


\section{CITIES AND INFECTIOUS DISEASES}

\section{P5-01 Increasing Incidence of Priapism Secondary to Intracavernosal Injection in HIV} Positive Males

M. Kogon; R. Stewart; J. Honey; K. Pace (St. Michael's Hospital, Division of Urology, University of Toronto)

Introduction: Priapism is a relatively rare urological emergency. We anecdotally noted an increasing incidence of priapism at our institution, and so we retrospectively reviewed all cases of priapism presenting to our emergency department over a threeyear period.

Methods: A 3-year retrospective analysis of patients with priapism presenting to the emergency department at St. Michael's Hospital, Toronto, Ontario, Canada (a tertiary care, academic urban teaching hospital, and regional trauma centre) was performed.

Results: A total of 18 episodes (16 patients, mean age 44) of priapism were identified. All represented ischemic (low-flow) disease. Thirteen emergency visits $(72 \%)$ occurred within the last year of the three years analyzed. Duration of tumescence ranged from 5 to 44 hours, with a mean of 20 hours. The majority of episodes $(83 \%)$ were secondary to intracavernosal injection, and of these, $73 \%$ occurred in HIV (human immunodeficiency virus) positive men. Most episodes of priapism resolved with cavernosal aspiration and/or phenylephrine injection. Operative intervention for detumescence was required in three cases $(17 \%)$.

Conclusion: A dramatic increase in the incidence of priapism secondary to intracavernosal injection in HIV positive males is described. This represents the first description of an association of priapism and HIV-positivity to our knowledge.

\section{P5-02 Factors Associates to the Death for Tuberculosis in Recife, PE, Brazil - Effect of Strategy DOTS}

Mirian Pereira Domingos; Waleska Teixeira Caiaffa; Antonio Enrico Colosimo (Pernambuco State Health Department ý Epidemiology Section)

Objectives: To evaluate death for tuberculosis (TB) before and after DOTS.

Methods: A population-based retrospective cohort design including patients recorded in the official TB-registry. Information on TB-death and HIV-AIDS was cross-verified in the Mortality and AIDS database. Census was the populationdenominator. TB-deaths and survivors were compared according to two timeperiod: pre-DOTS (1996-2000) and DOTS (2001-2004) and then multivariate analyses of all dataset was performed using time as exposure covariable.

Results: The incidence and mortality rates (100,000 inhabitants) were 96.6 and 12.2, in pre-DOTS and 129.7 and 8.2 in DOTS; the fatality rates were 12.3 and $9.0 \%$, for each period. The implementation of DOTS decreased the chance of TBdeath $(\mathrm{OR}=0.5$; CI95\% 0.4-0.7). In pre-DOTS, age, male gender, abandonment of previous treatment and combined clinical presentation were significantly associated to death. In DOTS, additionally to the later factors, calendar year, i.e., 2004, also associated to death when compared to 2003 (OR=0.3; CI95\% 0.2-0.5). Risk of death among those who abandoned treatment had higher magnitude in DOTS context $(\mathrm{OR}=4.2$; $\mathrm{CI} 95 \%$ 2.6-6.7).

Conclusion: Changes in TB indicators in this population suggested higher rate of disease detection and lower probability of death after DOTS implementation. Among non-HIV-AIDS patients, abandonment of previous treatment was still the most important factor in mortality. 


\section{P5-03 A Survey of Zoonotic Pathogens Carried by Norway Rats in Baltimore, Maryland, USA}

J. D. Easterbrook; J. B. Kaplan; J. Watson; W. K. Reeves; N. B. Vanasco; R. H. Purcell; M. Y. Kosoy; G. E. Glass; and S. L. Klein (The Johns Hopkins Bloomberg School of Public Health)

Norway rats are reservoirs for many zoonotic agents and are implicated in the transmission of pathogens to humans in urban environments. Because the resulting human diseases vary in their presentations and severity, the prevalence of rodentborne illnesses is thought to be underreported. As a first step in evaluating the importance of rat-borne pathogens for inner city residents, 201 Norway rats (Rattus norvegicus) were live-trapped in alleys in Baltimore, Maryland, USA from April 2005 - April 2006. Following trapping, rats were brought to the laboratory where they were sexed, weighed, and bled. Cecum and fecal samples were collected for microscopic determination of nematode egg burden. Serum was used to assess antibody production against several viruses, bacteria, and parasites by ELISA or IFA. Norway rats were infected with several zoonotic pathogens and were seropositive for Seoul virus $(57.7 \% ; 116 / 201)$, Hepatitis E virus $(73.5 \%$; 144/ 196), Bartonella elizabethae $(34.1 \%$; 63/197), Leptospira interrogans $(65.3 \%$; 124 / 190), Rickettsia typhi $(7.0 \% ; 14 / 201)$, and Ehrlichia spp. $(4.4 \% ; 4 / 91)$, but were seronegative for Lymphocytic choriomeningitis virus (0/48). Endoparasites, including Calodium hepatica $(87.9 \% ; 176 / 201)$ and Hymenolepis spp. $(34.4 \%$; 55/162), and ectoparasites (13.9\%; primarily Laelaps echidninus) also were present. Norway rats are potential reservoirs for a range of zoonotic pathogens. Evaluation of the potential spill-over to underserved human populations is warranted.

\section{P5-04 History of Childhood Sexual Abuse as a Predictor for HIV Risk Behavior in Severely Mentally III Puerto Rican Women in Cleveland, Ohio}

E. L. G. Heaphy, S. Loue; N. Mendez; I. J. Vargas (S. Hatters-Friedman, School of Medicine, Case Western Reserve University, Cleveland, OH) (Center for Minority Public Health, Case Western Reserve University)

We conducted this primarily qualitative study to examine the cultural context of HIV risk and protective behaviors among Puerto Rican women ages 18 to 50 years with diagnoses of schizophrenia, bipolar disorder or major depression $(n=53)$. Previous studies have demonstrated an association between childhood sexual abuse and high rates of HIV infection and HIV risk in Latina SMI women. Participants meeting study requirements were interviewed at baseline, annually for two years, and were shadowed for up to 100 hours over a two year period. We examined the data for patterns, themes, and categories that were developed and articulated by the participants and concepts brought to the study from a theoretical perspective. We calculated frequencies and chi square statistics to ascertain the association between outcome variables of interest and critical characteristics of the participants. A total of $36(67.9 \%)$ participants reported having been sexually abused during childhood. Sexually abused women were more likely to have used substances (Fisher's exact p-value $=0.05$ ) and to have abused substances (Fisher's exact $\mathrm{p}$-value $=0.05)$. Women who were sexually abused had a significantly greater number of sexual partners during a six month period (Fisher's exact p-value=0.006). Evidence suggests that Puerto Rican women with SMI who have a history of sexual abuse are significantly more likely to engage in HIV risk behaviors compared to Puerto Rican SMI women who were not subjected to childhood sexual abuse. Understanding the impact of childhood sexual abuse on current sexual and risk behaviors is critical for the development of an effective HIV intervention mechanism for this population. 


\section{P5-05 Bio-Med Cities}

\section{Hilary Sample (Yale University, School of Architecture)}

BioMed City

Cities worldwide are adopting a now-fashionable marketing strategyýthat of the BioMed City. For all that adopt it, the strategy encourages developing the most advanced public health care systems possible that focuses on high technology applications and research for facing potential threats to urban public health by combining research and commercialization. Its philosophical thrust forms a new paradigm for organizing a city and is based purely on the advancement and implementation of technologies associated with public health. The initiative resembles the themed cluster developments found across North America, like those of particular industries, where businesses and industries thrive on a density of people, land, buildings, and public infrastructures. But here in the BioMed City (BMC), as distinct even from a bio-science park, all proximities specifically support urban, public health, from research of communicable diseases to providing a mobile infrastructure for response to urban traumas and requires new partnerships of urban health experts, scientists, medical practitioners, urban planners, designer, and architects. Bio-Med Cities are the urban paradigm from Winnipeg to Amsterdam to Beijing. In addition, new types of buildings are being designed that merge critical laboratory space, with public gathering spaces under one roof and are found in the heart of downtowns, such as the MaRS project in Toronto. This work is part of a larger forthcoming book Sick City: A Global Investigation into Urbanism, Infrastructure and Disease, due out in Fall 2007. The book includes 40 maps and drawings by the author. The project begins by mapping the SARS outbreaks across cities world-wide and examines the effects on the city of Toronto, where I was teaching during 2003.

\section{ENVIRONMENTAL HEALTH}

\section{P6-01 Severe Lead Toxicity: A Changing Demographic Profile?}

Robert J. Borotkanics, MPH (Johns Hopkins Bloomberg School of Public Health) Background: This study leveraged the Healthcare Cost and Utilization Project (HCUP) to determine if there have been changes in the rate, demographic profile, regional concentrations and charges associated inpatient admissions resulting from lead toxicity. The study looked at a five year period across 11 states.

Methods: This research used population-level data, zip code information and US Census data to derive the rate and trends in the demographic profile of severe lead toxicity.

Results: Lead toxicity cases that result in inpatient admissions have declined over the time period in question. Cases span the full age range, with the overwhelming majority of cases realized before the age of five. Cases aged 0-4 and African Americans have experienced the greatest improvement. There have been no improvements in the Caucasian population. Cases in this racial category also tend to span the full age range, while African American cases are more isolated to the $0-4$ age category. Charges total nearly $\$ 9,000$ per case. Private insurers account for a large proportion of payments.

Conclusions: Inpatient cases are the most severe and very often lead to permanent damage. Severe lead toxicity is a low prevalence event that is preventable and could potentially be classified a sentinel event. Overall rates are improving; however, greater attention needs to be paid to both the full age range and also to the full span of racial groups impacted by severe lead toxicity. 


\section{P6-02 Poor Housing and III-Health in an Urban Community: Findings from a Population-Based Study in Lebanon}

Rima R. Habib; Ziyad Mahfoud; Jouman S. Yeretzian; Shiraz Basma (American University of Beirut)

Introduction: This research examined housing quality and health among residents of an underserved urban area, Hay el Sellom, near Beirut, Lebanon.

Methods: A survey based on a two-stage probability sample yielded 788 households with 3881 members of all age groups. The presence of chronic illness assessed ill health. Two indices measured housing quality: infrastructure and services and housing conditions. The analysis was done controlling for age, sex, displacement, educational level of the household head, household monthly income, and crowding.

Results: Problems with housing conditions related to poor ventilation, cockroach infestation, humid conditions, and seepage in walls. Problems with infrastructure related mainly to cuts in electricity and problems with sewage disposal. Households reporting four or more problems with housing conditions were $60 \%$ more likely to report the presence of illness than households reporting less than 4 problems (OR: 1.62, 95\% CI: 1.25-2.10). Indices on infrastructure and services did not show an association with the presence of illness.

Conclusion: This study helped to understand the general context of housing quality and its association with the health of residents in an urban community. Inadequate housing conditions were related to ill health. This calls for immediate action and stricter control on housing quality.

\section{P6-03 Urbanization, Waste Scavenging and Industrial Development in Nigeria: An Option Inevitable? \\ OLU-OLU OLUFAYO, PhD (DEPT. OF SOCIOLOGY, UNIV. OF ADO-EKITI, NIGERIA)}

The study examines the overriding effects of Urbanization of waste Scavenging and its influence on Industrial Development in Nigeria. The tremendous growth in waste generation, a by-product of Urbanisation and the resultant effect on Industrialisation of scavenging has been subject of controversy for some time now. The question, therefore remains whether waste scavenging remains a veritable source of raw materials for our growing industries and the inevitability of this for economic development in Nigeria. A representative sample of 1,913 workers cutting across some industries in the southwest were taken for the research, using the combined research instrument of questionnaire, observation, and focus group discussion methods. Findings revealed the health hazards posed by scavenging and the indifferent attitude of government towards this repugnant culture. It is, however, believed that the act of scavenging would remain a long feature of the Nigeran industrial system given our present economic situation. The study however made some recommendations for improvement.

\section{HEALTH INFORMATION TECHNOLOGY AND BEHAVIOR CHANGE}

\section{P7-01 Qualitative Analysis of Health Beliefs and Information Seeking Behaviors of Hispanic Women}

Joan E. Cowdery, PhD; L. Suzanne Suggs, PhD (Eastern Michigan University) The purpose of this presentation is to present the rationale, methods and results of a qualitative study designed to gain a better understanding of beliefs about health promotion and disease prevention that influence information seeking behavior 
among Hispanic women. Given the disproportionately high rates of diabetes, heart disease, stroke, HIV infection and breast cancer mortality among Hispanic women, as compared to Caucasians, it is important to better understand factors that influence health beliefs and information seeking among this population.

Three focus groups were conducted with a total of 24 Hispanic women in Boston, Massachusetts. Participants ranged in age from 18-39. The study examined sources of health information including access to technology, use of the internet, and suggested strategies for information dissemination among young, urban Latinas. These included use of email, online resources, and computerized tailoring of health communication messages. Results show that dominant themes emerged regarding health information seeking behaviors. Identified sources of health information were specific online sites and parents (particularly mothers). Interaction with health care providers was limited in this sample and consequently doctors were not identified as the primary health information source. Implications for health communication and information dissemination strategies specific to this population will be presented.

\section{P7-02 Access and Utilization of Information Technology among Minority Patients Attending Community Clinic in Los Angeles (LA)}

Magda Shabeen, MD, PhD; James Smith, MD; Richard Baker, MD (Charles R Drew University of Medicine \& Science)

Background: Experts in health care believe that lack of access to information technology (IT) is a contributing factor to the lack of delivery of health related IT to underserved communities. No information is available about access and utilization of IT among minority patients at community clinics.

Objective: To explore access and utilization of IT among patients attending community clinics in LA.

Methods: Cross-sectional survey of patients at two community clinics in LA. We interviewed using a questionnaire a systematic sample of 308 patients at the clinics and analyzed the data.

Results: The study included 308 patients, $18-82$ years (mean $=45, \mathrm{SD}=13$ ), $78 \%$ were female, $74 \%$ were Hispanics, $44 \%$ were married, $75 \%$ had income $<\$ 25,000$, $87 \%$ had $<$ high-school education, $55 \%$ were uninsured, $50 \%$ perceived their health status is fair/poor, and $12 \%$ were disabled. Most of the respondents had access to TV $(98 \%)$, radio $(94 \%)$, home phone $(80 \%)$, cell phone $(61 \%)$, and CD $(83 \%)$. Access to the computer and internet were $41 \%$ and $37 \%$ respectively. The major reason for not having computer/internet at home was cost $(50 \%)$. Of the internet users, $31 \%$ looked for health information on the internet. The common information searched was related to medical problem $(79 \%)$, diet/nutrition $(86 \%)$, and exercise/ fitness $(66 \%)$. Access and use of computer and internet were associated with gender, race/ethnicity, age and education $(<0.05)$. Most of the respondents reported that information received on the internet was helpful $(98 \%)$; improved the health services they received $(85 \%)$; and helped in health decisions-making $(85 \%)$.

Conclusions: Access and utilization of computer/internet was low among this population. Cost was the major barrier. Most of the internet users valued the importance, utility and usefulness of the internet in improving health service utilization and health related decision-making. Health promotion intervention using computer and internet might benefit these populations. 


\section{COMMUNITY APPROACHES TO URBAN HEALTH}

\section{P8-01 Prescription Access Ineligibility and Medication Non-Compliance: Using the Andersen and Aday Behavioral Health Care Utilization Model to Examine Preventable Primary Care Visits among Adult Uninsured Patients Ineligible for a Prescription Access Program at}

Jewel S. Goodman, MPA, PhD(c); Stacey B. Plichta, ScD; Qi Harry Zhang, PhD; Barbara Morrison-Rodriguez, PhD; Koren S. Goodman, MSEd (Pharmacy Care of Hampton Roads, Community Access to Care Program, Peninsula Institute for Community Health)

Most chronic diseases require on-going prescription management; without, increased exacerbations, preventable health visits, and poorer health are likely. Uninsured lowerincome adults with chronic conditions experience difficulty obtaining medications. This study examines effects of a stop-gap medication program operated by an urban community health center (CHC). The Andersen and Aday Model of Health Utilization was employed to examine predisposing, enabling and need factors associated with preventable visits. This 90 day observational study at collected data by patient survey and medical record abstraction at the multi-site $\mathrm{CHC}$ in two waves $(\mathrm{N}=427)$. Group membership was determined by stop-gap eligibility; the groups had similar demographic, disease and access characteristics. A vast majority report medication access difficulty in the past year. Almost all (93\%) report medication sharing, 89\% report not filling a prescription due to cost, and $76 \%$ report medication non-compliance due to cost. Most ( $84 \%$ ) of the 687 triage calls were from stop-gap ineligible patients who had been unable to obtain their medications and were experiencing symptoms. Of the ineligible group, $47 \%$ made appointments during follow-up, reporting symptom experiences and/or no medication access. If effective in minimizing symptom flare-ups and preventable health visits, stop-gap programs could be cost-saving and health promoting to CHCs.

\section{P8-02 Urban Community Dental Health Outreach Program}

Sharon Younkin, PhD; Kirsten Austad; Saurabh Saluja; Sean Spencer (The Allied Wellness Center)

University of Wisconsin-Madison undergraduate students, in partnership with a neighborhood non-profit, sought out community input to plan and execute a program to improve oral health awareness and prevent cavities in an over-burdened urban community. The product of this partnership was a preventive dental health project consisting of four dental clinics held in the neighborhood over the course of two months. The focus of these clinics was provision of fluoride varnish to neighborhood residents, a safe and inexpensive topical solution of sodium fluoride that when directly applied to teeth three times annually is effective at preventing childhood cavities. In addition, each participant was offered specifically tailored dental health education, oral hygiene supplies, and a dental screenings, to encourage and enable proper dental hygiene habits; a limited number of referrals to local dentists were offered for those with severe oral health problems. Surveys assessing knowledge, habits, and efficacy related to dental health were used for program evaluation.

Our poster will give an overview of the project, including a summary of program components (interactive education stations, dental screenings, and fluoride 
varnish) and survey results. Additionally, the poster will explore the challenges in the development of a partnership between a multi-ethnic underserved community, a very small (one part-time employee) community health organization, and a large academic institution. We will also communicate the methods used to successfully engage undergraduate students in this project. Participating students learned firsthand about health disparities, were able to interact with members of an underserved neighborhood, and increased their understanding of the importance of oral health and the barriers this community faces in achieving good overall health.

\section{P8-03 Community Perspectives Regarding Fairness in Health Care Resource Allocation Decisions}

Ahmed M. Bayoumi, MD, MSc, FRCPC (Epidemiology and Health Care Research Program, Department of Health Policy, Management, and Evaluation, University of Toronto, and Centre for Research on Inner City Health, St. Michael's Hospital) Introduction: Health care resources decisions must balance efficiency and equity, particularly when health benefits accrue at high costs. We explored the concept of fairness in resource allocation from the perspective of community members.

Methods: 4 focus groups ( 2 men / 2 women; 2 general population; 2 people living with HIV)

Results: We identified 6 themes: 1) Efficiency is important, but should be defined broadly. It may be defensible to withhold resources when treatment is futile or the return on investment is slim; 2) Alongside efficiency, resource allocation decisions should value compassion and equity; 3) Resource allocation decisions are inherently complex, involve difficult trade-offs and may lead to situations where individual values may be compromised; 4) Many do not want to be involved in such decisions. Alternatives include nominating others to make decisions or putting trust in research to find solutions; 5) Resource allocation decisions are viewed as inherently political and somewhat cynically. 6) Some see solutions in working outside of official systems.

Conclusions: Community members have a good appreciation for the complexities of resource allocation decisions but are often reluctant to partake in such processes. Our findings have implications for the movement to involve consumers in policy-level decision making.

\section{P8-04 Profile of the Patients Who Use Psychotropic Medication, an a City in the South of the Brazil}

AuthorAna Guilhermina Reis; Ana Paula Schulz; Luci Borba Canabarro; Regina Ledo Beneri (Health of the Employees of the Bank of Brazil. School of Public Health) Background: In the basic care, the Strategic Family Health comes to promote the prevention, diagnosis, treatment and rehabilitation during the whole lifetime, including the mental health. Thus, the current research has aimed to characterize the Strategic Family Health patient profile from the city Barra do Ribeiro, RS, Brazil, who take the psychotropic medication, verify which are the most prescribed psychotropic medication according to the records and suggest actions to improve health and to prevent drugs abuse.

Methodology: The methodology used was the exploratory-descriptive with a quantitative approach. The sample was made of three hundred patient medical history, who had had a medical consultation, from January 2005 to September 2006.

Results: The database shows that the patients profile, who take psychotropic medication, are in the majority women, aged between 60 and 65 , having as the main cause of the use the depression, being the most used medication Fluoxetina $20 \mathrm{mg}$, with 2 years of use and prescription from psychiatry non-specialists. 
Conclusion: The results, from this research, will be able to contribute to the awareness of Passo da Estancia Family Health Team and Barra do Ribeiro Health Secretary related to the importance of developing projects for Mental Health Care in the Strategic Family Health, grounded in the principles of Health System (SUS) and the Psychiatric Reform, in order to qualify and humanize the assistance.

\section{P8-05 A Pilot Study on the Body Composition and General Health}

\section{A. Suleiman; Narimah; A. D. Krishnapillai (UITM, SHAH ALAM)}

Objective: This objective of this study is to assess the body composition which may affect the risk of blood pressure, heart disease and diabetes among the urban and rural populations in Malaysia.

Methodology: A cross-sectional study was conducted in 2 Health Clinics in Kuala Lumpur (urban) and 2 Health Clinics in Teluk Intan, Perak (rural) within 1 week in August and November 2006 to investigate the quality of life among urban and rural populations in Malaysia. Structured questionnaires were given using systematic random sampling to 248 respondents from the urban and 104 from the rural populations. The respondents were also measured for Body Mass Index, Waist-Hip Ratio and blood pressure. The data were collected and analyzed using SPSS version 13.0.

Results: The mean age was $46.4+16.1$. Malays formed $63.7 \%$ of the population in Urban areas and $74 \%$ of Rural population. Females formed about $42 \%$ of the population in both urban and rural setting.

There was no significant difference among urban and rural population with reference to BMI $(\mathrm{X} 2=6.84 \mathrm{P}=0.077)$. There was significant difference in $\mathrm{WHR}$ among the population in urban and rural areas $(\mathrm{X} 2=5.73, \mathrm{P}=0.017)$. There was significant difference in the occurrence of Diabetes Mellitus $(\mathrm{X} 2=7.69 \mathrm{P}=0.021)$. and Hypertension $(\mathrm{X} 2=12.5$ $\mathrm{P}=0.006)$ between urban and rural population. However, there was no significant difference in the blood pressure whether systolic $(\mathrm{X} 2=3.02 \mathrm{P}=0.221)$. or diastolic $(\mathrm{X} 2=$ $0.88 \mathrm{P}=0.646)$. among rural and urban when it was taken during the study.

\section{IMMIGRANT \& REFUGEE POPULATIONS}

\section{P9-01 Peculiarities of Refugee Population in African Society}

Kodjovi Marvis; Kodjovi Olaitan Fausiat (Aids prevention initiative nigeria (APIN), student attachee.)

A Refugee is a person who has fled or been expelled form his/her country of origin because of war military occupation, natural catastrophe or fear of religious, racial or political persecution. Africa with more than fifty (50) Nations and seven thousand, intensified as the world population continually increases, mostly in the countries least able to provide +for its inhabitants. This movement has a major communal or society implications ranging from problems of housing, begging, prostitution and other social menace.

It also has its health implications; drug abuse, unwanted pregnancies, teenage mothering and dreaded HIV/AIDS. Currently legal protection and material assistance are provided to refugees by the UNHCR.Efforts should be made to get international Govt. refugee agencies to work, closely with other national and international agencies. With enhanced economic/political stability and the necessary political will on the part of Government in Africa nations, problems of the refugee populations can be greatly mitigated. ix hundred (7600) groups has about one-third (1/3) of the world refugee. These people uprooted by famine or liberation struggle escaping racial and ethnic 
oppression and economic hardship, because of the political and economic crisis, deprivation of human right, civil war, lack of food and other resources. The large movement of refugees is bound to continue and even intensified as the world population continually increases, mostly in the countries least able to provide for its inhabitants. This movement has a major societal implications ranging from problems of housing, begging, prostitution and it also has its health implication; drug abuse, unwanted pregnancies, teenage mothering and the dreaded HIV/AIDS. Currently legal protection and material assistance are provided to refugees by the UNHCR.

Effort should be made to get international govt., refugee agencies to work closely with other national and international agencies. With enhanced economic/ political.

\section{SUBSTANCE ABUSE AND MENTAL HEALTH}

\section{P10-01 Improving Access to Appropriate Care for ER Frequent Users}

Karen Swanson, PhD, ScM, Jose C. Salazar, DrPH, Nanette Litturi, MA, LCPC (Los Angeles County Department of Health Services)

Project Improving Access to Care's (PIAC) aim is to reduce frequent user's high ER utilization through having case managers (CMs) link them to appropriate community-based care.

An electronic flag appears on the CMs' computers when a patient makes his/her $>=5$ th ER visit in the past year. If these patients are uninsured or have Medi-Cal, and present with $>=1$ of the following conditions: mental illness, substance abuse, or homelessness, they are assigned to CMs who do an intake interview, needs assessment, and then refer them to community-based organizations for care.

An analysis of this ongoing intervention was performed $(\mathrm{N}=89)$ by comparing ER utilization six months before and after project enrollment. The control group was created from 49 non-PIAC randomly selected sex-matched patients with similar utilization.

The PIAC and control group decreased their respective mean visits by 3.2 and 1.7. Though $\mathrm{p}=0.08$, this could be due to the small sample size of this preliminary analysis.

Hospital administrators could implement intensive CM models in their ERs with electronic notification so that frequent users' vicious cycle of repetitive ER use could be broken and care be redirected to meet their underlying needs, be it primary care, mental health care, housing, and/or substance abuse treatment.

P10-02 Prevalence and Correlates of HIV among Injection Drug Users in Tijuana, Mexico: Individual, Social and Environmental Vulnerabilities

S.A. Strathdee; R. Lozada; K.C. Brouwer; A. Mantsios; R.A. Pollini; J. Alvelais, D. Abramovitz; R.S. Garfein; O. Loza; P. Case; C. Rodriguez-Magis; T.L. Patterson (University of Calif San Diego School of Medicine)

Background: Concerns over increasing drug use and HIV transmission in Tijuana, Mexico (adjacent to San Diego, CA) prompted a study of risk factors among injection drug users (IDUs).

Methods: IDUs aged \&\#8805;18 years were recruited into an ongoing prospective cohort using respondent driven sampling (RDS) and underwent interviews and antibody testing for HIV and syphilis. Weighted logistic regression identified correlates of HIV infection. 
Results: To date, of 986 IDUs, median age was 37; 89\% were male. Overall HIV prevalence was $3.9 \%$, but higher in females than males $(10.0 \%$ vs. $3.1 \%$, p= 0.002 ). Median number of injection partners in the prior 6 months was 2 . Median number of arrests for having track-marks was 2. Factors independently associated with HIV-positive serostatus were being female (AdjOR: 3.41), number of years lived in Tijuana (AdjOR=0.73 per 10 years), syphilis titers \&\#8805; 1:8 (AdjOR= $3.54)$, being arrested for track-marks (AdjOR $=1.02$, per arrest) and number of recent injection partners (AdjOR $=1.04$, per person).

Conclusions: Individual, social and environmental factors were independently associated with HIV infection. Females, migrants, those injecting with others and infectious syphilis cases were more likely to test HIV-positive, indicating the need for targeted HIV/STD testing and treatment. Efforts to stop arrests for track-marks are urgently needed.

\section{P10-03 Narratives of Absence and Absences of Narratives: Is Homelessness an Act of Forgetting?}

Manal Guirguis-Younger; Ryan McNeil (Saint Paul University)

Research conducted involving friends, family members, and careworkers of persons who are homeless in the Ottawa-region raises an important question regarding coping strategies: Is homelessness a way of dealing with traumatic experiences? A social autopsy investigating contributing factors into the deaths of twenty-three persons who were homeless suggests that homelessness may be used to forget trauma. In Narratives of Absence and Absences of Narrative, we explore how, for persons who are homeless that have experienced traumatic events such as childhood emotional, physical, and/or sexual abuse and lack effective support systems, becoming homeless may be a way to eliminate everyday reminders of these events. These acts of forgetting are manifested in the personal narratives of persons who are homeless in several key ways: first, how they do not share personal stories with others regarding past experiences; second, how defense mechanisms, such as threatening behavior, prevent others from gaining access to or believing their stories; and, third, how substances may be used to distract from traumatic events, thereby focusing persons on immediate needs and presenting another pathway to homelessness. This research suggests a further need for further screening and therapeutic interventions to assist persons who are homeless who have experienced traumatic events.

\section{P10-04 Suicidal Behaviour on Subway Systems: A Review of the Epidemiology}

Ruwan Ratnayake; Paul S. Links; Rabel Eynan (Independent (currently). Suicide Studies Unit (at time of study).)

Suicidal behaviour on subway systems has been reported across urban centres worldwide. Our objective was to analyze studies of suicidal behaviour on subway systems, develop a profile of characteristics that are suggestive of association with suicides or attempts, and show how this profile can inform prevention. A review involving 28 epidemiology studies and other studies of suicidal behaviour on subway systems was conducted. Across studies, characteristics were not often assessed for risk factor status although several characteristics were remarkably similar. Those attempting suicide on the subway appear to be affected by serious mental illness and have contact with mental health services prior to the event. The population appears to be 2030 years of age and predominantly male, but with a smaller gender difference as compared to the proportions for all causes of suicide. They may have a high level of lethal intent and may express a desire to commit suicide prior to the incident. Shared 
temporal- and station-based characteristics are also described. While well-designed studies that utilize robust data collection and statistical methods are needed to establish risk status, the shared characteristics emphasize the potential for prevention in the clinical, public health and engineering-based domains.

\section{P10-05 Community Outcomes for Persons with Mental Illness Released from State Prison to Philadelphia}

Stephen Metraux, PhD (University of the Sciences in Philadelphia)

This paper examines incarceration and community outcomes among persons with mental illness who were released from prisons administered by the Pennsylvania Department of Corrections (PADOC) to Philadelphia locations. Analyses utilized administrative data from prison, jail, community mental health, homeless services and police for 12,000 persons - all of the PADOC records for persons released from prison between 1999 and 2002 to Philadelphia locations. Results show that mental illness indicators were associated with greater difficulty obtaining parole, greater likelihood of reincarceration, and greater likelihood of shelter use. Low rates of Medicaid eligibility were also found, indicating difficulties in accessing community mental health services following prison release. The results support previous research that mental illness mitigates successful transitions from prison back to the community.

\section{CULTURAL AND ETHNIC DIVERSITY IN URBAN HEALTH}

\section{P11-01 El Paso Health Occupations Literacy Project}

\section{Souraya Hajjar, MPH, ABD (El Paso Community College)}

The project originated from a need for Health Literacy awareness assessed by the community health professionals and educators. It targeted Middle School students for their role in health information translation for parents, and/or grandparents; in assimilating information at this age, and assisting the overall health of families since the majority does not have access to healthcare. Three School Districts were targeted.

The Health Literacy Middle School Curriculum dealt with the following topics:

- Community and Environmental Health

- Mental and Emotional Health

- Personal and Consumer Health

- Alcohol and Other Drugs

- Nutrition

The project hired more than 8 health literacy trainers (all are healthcare professionals or health occupations students) to implement the Health Literacy Middle School Curriculum in the 3 districts. The program started with a preassessment of their health knowledge and understanding. Trainers and current school teachers go over the schedule for 18 weeks, during which students are taught the Health Literacy curriculum.

Once all topics are presented to the Middle School students, students are given a post-assessment test to test their knowledge of Health Literacy according to the curriculum topics presented. Results of pre-and post tests showed general anecdotal increase in health knowledge in MS students.

Successful implementation of the Health Literacy curriculum in El Paso County and increase of health awareness and knowledge in the target population to 
eventually incite policy makers on the State level to adopt a health literacy section in the State adopted Middle School curriculum.

\section{OTHER}

\section{P12-01 Workplace Violence in Nursing Personnel: Findings from the Baseline Questionnaire}

Jacquelyn Campbell, PhD, RN, FAAN; Joan Kub, PhD APRN, BC; Jacqueline Agnew, PhD, RN, FAAN; Sheila T. Fitzgerald, PhD, RN; Barbara Fowler, PhD; Daniel J Sheridan, PhD, RN, FNE-A, FAAN; Richelle Bolyard, BA (Johns Hopkins School of Nursing)

Workplace violence (WPV) has major long term health and employment implications for nursing staff (professional nurses and other nursing personnel - aides, technicians, transport service employees etc.) Hospital workers have 4 times greater risk for WPV than private sector employees (Bureau of Labor Statistics, 1999). Workplace violence is defined in this prospective study as physical assaults, psychological and sexual abuse, harassment, stalking and vicarious violence. Outcomes of WPV may include reduced productivity, absenteeism, presenteeism, and job dissatisfaction. Health and employment outcomes at Baseline of an 18 month prospective study of nursing personnel (professional and nonprofessional) at 1 medical institution comprised of 2 large urban and 1 suburban hospital will be presented. Differences between level and types of WPV experienced by urban personnel versus suburban personnel and professional nurses in comparison to other nursing personnel will be analyzed along with risk factors for WPV and physical and mental health symptoms. We anticipate that $(\mathrm{N}=1100)$ nursing staff will have experienced WPV during the year prior to study initiation. These cases will be compared to a randomly selected group of nursing staff from these settings $(\mathrm{N}=600)$ who have never experienced WPV. Analyses of episodes of WPV (prevalence and contributing factors), including violence type, injury, reporting, organizational response, and any interventions will be conducted. These preliminary study results about WPV in the healthcare setting and the factors influencing negative health and employment outcomes for urban hospital nursing personnel will eventually determine the development of workplace policies and prevention strategies. Given the sensitive nature of the topic, IRB and COC have been obtained. Referral information to counseling services, safe houses, staff assistance programs, law enforcement agencies, and community organizations is provided for all participants.

P12-02 Impact of Municipal Finances on Medical and Health Services in PimpriChinchwad Municipal Corporation Urban Area

Mrs. Asha K. Khillare (Senior lecturer in Economics); Dr. B.S. Mhaske (Retired Professor in Economics) (MES Garware College Of Commerce, Pune, India)

Objectives:

1. To analyze the trends in expenditure on Medical and health services of PimpriChinchwad Municipal Corporation (PCMC).

2. To examine the trends in revenue from Medical and health services of PCMC.

3. To study correlation between Municipal finances and health care in urban area.

Methodology: This study is based on secondary data collected from Annual budget documents of PCMC. Simple Statistical tools like percentage, growth rate, average, and regression are used for the purpose in hand.

Period of Study: This study covers the period of 5 years that is from 2000-01 to 2004-05. 
Observations: Of the total expenditure (Capital and revenue), PCMC spent 60.94 percent on Public Health, 24.19 percent on Medical Services and 14.87 percent on Yashwantrao Chavan Memorial Hospital (YCMH). The revenue expenditure of PCMC (on an average 71.27 percent) is relatively more than capital expenditure (28.73 percent). It is worth noting fact that PCMC spent large part of its total revenue expenditure on establishment (69.97 percent) and very meager amount has been spent on purchase of medicine and instruments (10.81 percent) and solid waste management (6.57 percent). Though maximum expenditure is titled in favor of establishment, PCMC provides very unique and adequate medical facilities to its inhabitants in urban areas.

Conclusion: It can be inferred that PCMC spent relatively more on establishment than other items. Its recurring expenditure exceeded capital expenditure which needs to be rationally allocated. Moreover, PCMC incurred very less expenditure on purchase of medicine and instrument, solid waste management etc. Despite PCMC is proved to be efficient in delivering urban health care services.

\section{P12-03 Traumatic Brain Injury among Homeless Persons}

Stephen W. Hwang (Centre for Research on Inner City Health, St. Michael's Hospital); Angela Colantonio (Department of Occupational Science and Occupational Therapy; University of Toronto); Shirley Chiu (Centre for Research on Inner City Health, St. Michael's (Centre for Research on Inner City Health, St. Michael's Hospital)

Objectives: To examine the prevalence of traumatic brain injury (TBI) in homeless people in Toronto, Canada, and temporal relationships between TBI and onset of homelessness.

Methods: Randomly selected single homeless persons at 68 shelters and meal programs provided self-reported information on lifetime history of TBI. Mild TBI was defined as a head injury that left the person dazed or confused, but resulted in no loss of consciousness (LOC) or LOC $<=30$ minutes. Moderate/severe TBI was defined as a head injury resulting in LOC $>30$ minutes.

Results: 604 males and 303 females were interviewed. Lifetime prevalence of TBI was $53 \%$ and significantly higher among males than females $(58 \%$ vs. $42 \%, \mathrm{p}=$ $0.0001)$. Prevalence of moderate/severe TBI was $12 \%$. Among individuals with history of TBI, $72 \%$ had their first episode of TBI before the onset of homelessness. Median age at first TBI and first moderate/severe TBI was 14 and 16 years, respectively.

Conclusions: The prevalence of TBI was very high in a representative sample of homeless people in Toronto. TBI often occurred during adolescence and usually antedated the first homeless episode, raising the possibility that TBI causes cognitive or behavioral problems that contribute to the onset of homelessness. Clinicians should assess homeless patients for history of TBI and consider TBI as a possible cause of neuro-psychiatric dysfunction.

P12-014 Comparison of the Characteristics and Psicosocial, Structural and Individual Risk Factors that Promote the Homelessness Between Chronic and No Chronic Homeless on Caguas Puerto Rico Municipality

Joanny Mercado, PhD; Aida L. Garcia, PhD; Juan Nogueras, PhD (Coaliciýn Criolla de Cuidado Continuo del Minucipio Autonomo de Caguas, Universidad Carlos Albizu)

The problem of homelessness had been elucidated in according with the distinction or the definition of chronic or no chronic homeless; because, there are some differences between them that we have to indicate in order to understand more the dynamics of 
homelessness. A sample of 113 participants was obtained and divided in according with the Federal Register (2004) definition of chronic or no chronic homeless. The $39.5 \%$ on the no chronic homeless group indicated that used substance and the $48.0 \%$ of the chronic homeless indicated as well. On both groups we observed the psicosocial risk factors as neglect by the parents, drug abuse and maltreatment on childhood and on familiar life. We observed structural risk factors as unemployment and low economic resources. The chronic homeless reported more the childhood problems and individual factors as the reason for homeless and the no chronic group reported the detachment and lost from family and low resources as the principal reasons for their homelessness. The homeless confront an infinity situations and physical conditions that become them vulnerable to many others problems. As result, they fall on the homelessness cycle specialty on chronic homelessness.

\section{URBAN DISASTERS}

P13-01 Disaster, Gentrification, and the Future of Cities: How Migration and Disintegration Affects Community Health

Shekinah Elmore; Laura Gabby (Gulf Coast Recovers)

Hurricanes Katrina and Rita provide catastrophic examples of the ways in which disaster can reshape the urban and health environments of the disenfranchised. Yet, less recognized but more pervasive examples of disaster, such as gentrification and neo urban renewal, persist unabated in most major cities in the United States. This presentation will highlight the similarities between the health consequences of the 2005 hurricanes in New Orleans, LA and the gentrification and displacement caused by ongoing renewal projects in New York, NY. Both types of disaster cause an upheaval of residents, which leads to the destruction of the social ties crucial to health. Community-based and community-directed options for ameliorating the deleterious effects of migration and disintegration will be explored.

\section{URBAN HEALTH AND GIS}

\section{P14-01 Social and Spatial Determinants of Alcohol-Related Traumatic Brain Injury in Three Canadian Cities}

M. Cusimao; S. Marshall; M. Chipman; C. Rinner; R. Glazier; T. Hernandez; K. Jones; T. Bekele (Injury Prevention Research office, St. Michael's Hospital, University of Toronto)

Objective: The purpose of this study was to determine the socioeconomic and local land use characteristics associated with high rates of alcohol-related traumatic brain injury.

Methods: Using the Ontario Trauma Registry Comprehensive Database, rates for alcohol-related TBI were calculated for the Forward Sortation Area level geography for three Ontario cities for three age groups (15-24, 25-64, 65 and older), for both intentional and unintentional injury types. These rates were then compared to local socioeconomic indicators and the distribution of alcohol retailers and drinking establishments.

Results: In the youth and adult populations, traffic-related injury was found to be the most common cause of alcohol related TBI in all three cities. In the senior population, fall injuries were the most common cause. The variation in the rate of alcohol-related TBI was related to several local indicators of social deprivation, a finding that is shared amongst all three urban centres. 
Conclusions: There are several implications for injury prevention and control. Areas with high rates alcohol-related TBI are not randomly distributed. The socioeconomic characteristics of alcohol-related TBI patients are similar to those in other studies, and geographic areas can be isolated based upon those characteristics. With some exceptions, the locations of neighbourhood bars and pubs appear to correspond to the risk demographics.

\section{DEMOGRAPHICS: AGING/GENDER/ETHNICITY}

\section{P15-01 Gender Inequalities and Rights of Vulnerable Population}

Dr. Rafiush-shan Ahmad; Rana Gulzar; Nusrat Yasmeen (Bolan Medical Hospital) Introduction: Basic human rights are often denied to high-risk populations and people living with HIV/AIDS. Their rights to work and social security, health, privacy, nondiscrimination, liberty and freedom of movement, marriage and having a family have been compromised due to their sero-positive status and risk of being positive. The spread of HIV/AIDS has been accelerating due to the lack of general human rights among vulnerable groups. To formulate and implement effective responses needs dialogue and to prevent the epidemic to go underground barriers like stigma need to be overcome.

Objective: How to reduce the situation of stigma, discrimination and human rights violations experienced by people living with HIV/AIDS and those who are vulnerable to HIV/AIDS.

Methodology \& Findings: Consultation meetings were structured around presentations, field visits, community meetings and group work to formulate recommendations on how Govt and NGOs/CBOs should move forward based on objective.

Pakistan being a low prevalence country, the whole sense of complacency that individuals are not subject to situations of vulnerable to HIV is the major threat to an explosion in the epidemic, therefore urgent measures are needed to integrate human rights issues from the very start of the response.

The protection and promotion of human rights in an integral component of all responses to the HIV/AIDS epidemic. It has been recognized that the response to HIV/AIDS must be multi sectoral and multi faceted, with each group contributing its particular expertise. For this to occur along with other knowledge more information is required in human rights abuses related to HIV/AIDS in a particular scenario.

Recommendations: The need for a comprehensive, integrated and a multisectoral approach in addressing the issue of HIV/AIDS was highlighted. The need social, cultural and religious aspects to be prominently addressed were identified.

\section{P15-02 Demographic Profile of Slum Dwellers in Pimpri Chinchwad Municipal Corporation Urban Area.}

Dr. Kishor Khillare; Dr. Nagkumar Kunachgi (Pimpri Chinchwad Municipal Corporation, Pune, India)

Objectives: To know age, gender and sex ratio; Assessment of socio economic and educational status; To find and analyze health status, maternal health and family structure; To study health behavior (habits)

Methodology: 394 out of 657 families (slum dwellers of an unauthorized slum habitat known as Shantinagar in Pimpri Chinchwad Municipal Corporation) were surveyed in November and December 2006.

Observations: Age wise distribution shows $0-5$ yrs $13.2 \%, 5$ ý 15 yrs $23.5 \%, 15-$ 30 yrs $34.5 \%, 30-45$ yrs $19.3 \%, 45-60$ yrs $7.2 \%$ and $60-75$ yrs $2.3 \%$. Sex Ratio 
reveals 902 females per 1000 males. Social structure constitutes down trodden Scheduled caste $84 \%$, Scheduled Tribe $4 \%$ and other backward class $6 \%$ whiles other castes $7 \%$.

Economic status shows families with monthly income of Rs 500 -1000 1.3\%, Rs 1000- 5000 72.4\%, 5000-10000, 22.6\% and Rs $10000-200000$, 3.7\% (1 Dollar = Rs 41). Occupation: $52.3 \%$ irregular daily wages labor, $36.2 \%$ contractual labor, $3.7 \%$ service, $2.3 \%$ business and $5.5 \%$ others.

Average family size is 4 persons per family. Family type Nuclear $84.3 \%$, Joint $13.5 \%$ and other $2.2 \%$

Health status indicate evidence of Anemia 13.4\%, TB 1.2\%, Other respiratory illness $6.8 \%$, Diabetes Mellitus $0.3 \%$ Hypertension $0.4 \%$, Malnutrition $0.8 \%$ and No illness 73.9\%. Maternal health shows ANC 2.7\%, PNC 2.2\%, Adolescent $17.6 \%$; Health behavior habits pattern was tobacco $11.2 \%$, Smoking $6.7 \%$, Alcohol $9.3 \%$ and other $1.4 \%$

Conclusions: Demographic study explores health needs and intervention programme in community.

Sex ratio is slightly better 902 females as compared to PCMC (893/1000 males). $88 \%$ of population belongs to down trodden castes.

Majority of population $(72.4 \%)$ lives with 24 to 122 dollars monthly income. $88.5 \%$ are laborers by occupation. Average family size is 4 .

Anemia, Other respiratory illness, dental caries and TB are major illnesses.

Behavioral change needed to change bad

\section{P15-03 Racial/Ethnic Differences in Self-Assessed Health Status}

Rashida Dorsey, PhD MPH; Mark Eberhardt, PhD (National Center for Health Statistics, Centers for Disease Control and Prevention)

Self-assessed health status can describe the impact of chronic disease on individuals. We examined race/ethnic differences in health status in the general population and among persons with chronic conditions, using nationally representative data.

Analysis consisted of 15,329 men and women aged \&\#8805; 20 years from the National Health and Nutrition Examination Survey, 1999-2004. Respondents rated their health as excellent, very good, good, fair, or poor.

Overall, $17 \%$ of the population reported fair or poor health. Mexican-Americans (age-adjusted $\mathrm{OR}=3.1 ; 955 \mathrm{CI}=2.6,3.8$ ) and Non-Hispanic blacks (age-adjusted $\mathrm{OR}=$ $2.2 ; 95 \% \mathrm{CI}=1.8,2.7)$ were more likely to report fair or poor health, compared to NonHispanic whites. After adjustments for age, gender, insurance status, education level and history of diabetes, cancer, or cardiovascular disease, Mexican Americans $(\mathrm{OR}=1.9$; 95\% CI $=1.6,2.2$ ) and Non-Hispanic blacks (OR=1.6; 95\% CI 1.3, 1.9) were more likely to report fair or poor health compared to Non-Hispanic whites. Similar race/ ethnicity patterns were found among persons with cardiovascular disease and diabetes.

Racial/ethnic minorities reported lower health status compared to Non-Hispanic whites, even after adjustments for SES, access and comorbidities. Continued research to identify the factors causing these disparities is warranted.

\section{P15-04 Improving Services to a Diverse Population of Urban Elders}

Patricia M. Alt (Towson University); Tracy Gibbs (Baltimore City Commission on Aging and Retirement Education); Russell Morgan (SPRY Foundation); Robert Bertera (Evaluation Research) (Towson University)

Building on a baseline study of key community informant interviews, stakeholder focus groups, and current literature, the Aging Communications Training (ACT) project developed and implemented a training curriculum to improve direct services to 
the very diverse population of older adults in Baltimore City. The individuals trained were senior center assistants and volunteers, Meals on Wheels volunteers and van drivers, and entry level case managers. The goal was to enhance the ability of direct care employees and volunteers to understand and serve Baltimore's growing population of independent-living older adults of varying ages, cultures, mental capacities, and socioeconomic levels. Training included basic knowledge about aging, exposure to issues caused by sensory and mental health changes, dealing with the client's living environment, and stress reduction for the service providers themselves. Funded by the Retirement Research Foundation and the SPRY Foundation, in partnership with the Baltimore City Commission on Aging and Retirement Education (CARE) and the National Association of Area Agencies on Aging (n4A), we trained 60 employees and/ or volunteers in the spring of 2007. Pre- and post-test assessments were done to measure aging and communications knowledge, beliefs, and self-efficacy. The program will be disseminated nationally, beginning with the n4A national meeting in July.

\section{COMMUNITY PARTNERSHIPS}

\section{P16-01 Developing a Community-University Partnership to Enhance Community- based Participatory Research and Practice}

James Butler, DrPH (University of Pittsburgh Graduate School of Public Health)

Developing a comprehensive approach to Community-based Participatory Research and Practice (CBPRP) involves schools of public health to increasingly engage in community-university partnerships with community organizations. The main tenant of this approach is the community is at the center of the development, implementation and analysis of research and practice. Both the university and the community have common interests, responsibilities, privileges and power. Trust between the parties is built and needed strategies for improving the health of the community are co-defined. Further, this approach links public health students and practitioners with the academic quest to advance understanding and the needs of the community. We describe a newly formed partnership between a community service provider and a school of public health to enhance CBPRP. This partnership promotes graduate level and community education, participatory research and service projects, and internships for students. To date, the partnership has developed a permanent classroom presence by conducting selected graduate level courses in the community. Future projects include increasing student internships, providing community education classes, and conducting joint participatory research and service projects between the university and the community.

\section{P16-02 BRANCH OUT: A Faith Based Partnership to Promote Health and Wellness}

Staci Young, MS; Syed Abmed, MD (Medical College of Wisconsin)

The purpose of the BRANCH (Building a Rejoiceful Alliance of Neighbors for Change and Healing) Out partnership is to reduce health risk factors related to cancer, cardiovascular disease, and diabetes in African-American church-based communities in Milwaukee. Churches have a strong tradition of caring for others, providing fellowship, support and education. BRANCH Out builds on the existing relationship between health ministry workers and congregation members to address the social determinants of health. BRANCH Out has the following objectives: 1) develop and train Church Health Action Teams (CHATs) at participating churches; 
2)develop, implement and disseminate cancer, cardiovascular disease and diabetes risk reduction education and prevention materials and resources; 3)develop and implement cancer, cardiovascular disease and diabetes risk reduction best practices at churches; and 4)sustain, evaluate, and expand the program. We will highlight the development of a partnership between the Center for Healthy Communities in the Department of Family and Community Medicine at the Medical College of Wisconsin, the City of Milwaukee Health Department and seven African-American churches in Milwaukee. The project utilizes a community health worker/train-thetrainer model to effectively deliver culturally and literacy appropriate health information to community members. 25 Church Health Action Team (CHAT) members have been recruited and trained. Training sessions included presentations and discussions on spirituality and health; stages of health behavior change; nutrition; community resources; team building and goal setting. CHAT members reported an increased understanding of the training topics and services available. Our partnership recognizes the myriad of factors that influence the health status of community members. Recognition of these dynamics allows the partnership and the project to effectively address the health needs of the community.

\section{P16-03 The Junior Fellows Program: Advancing Middle School Students' Interest in Careers in Health, Science and Medicine Using Technology, Project-Based Learning and Role Models from the Health Professions}

Leslie Goldman, MA; Joanne De Simone Eichel, MA; Sejal Gandhi, MA, CHES (The New York Academy of Medicine)

The Junior Fellows Program, a partnership between The New York Academy of Medicine Office of School Health Programs and the Academy Library, New York City public schools, and regional Academic Medical Centers, is designed to stimulate middle school students' interest in careers in health, science, and medicine. The program is designed to advance students' skills in using technology-based educational resources, including an interactive website, www.juniorfellows.org; identifying concrete strategies for improving health and preventing illness; and understanding the research process and the nature of scientific inquiry. To date, more than 800 students have participated in the program.

Since its inception, the program has worked to enhance educational opportunities for urban public school students and promote career awareness for the health professions, with a special emphasis on improving the proportion of minorities and women who enter these fields. The 10 month course of study engages students in project-based learning, works to enhance their critical-thinking skills, and helps them to foster positive interactions with practicing health professionals. Upon completion of the course, students present their research summaries at a poster session to experts in the fields of health, science and medicine.

The Academy has initiated The Scholars Program: Science Enrichment and Career Awareness for Junior Fellows alumni as they move into high school and beyond. The program provides educational experiences to assist the Scholars in pursuing careers in health, science, and medicine. The Scholars gain an in-depth view of the lives, careers and scientific expertise of professionals in these fields and develop a foundation of knowledge and skills needed to successfully pursue careers in these areas. The Scholars use technology to engage in online dialogs and explore current issues, trends and news with experts in science and medicine through the website. 


\section{P16-04 Partnering with Communities to Enhance Recruitment of Youth into Drug Prevention Research}

Craig S. Fryer; Paul Pelmon; Shannah Tharp-Taylor; William G. Shadel (University of Pittsburgh, Graduate School of Public Health)

A growing body of evidence illustrates the difficulty investigators face in the recruitment and retention of youth into drug prevention research and programming. Community partnering has received increased attention as a method to enhance research design and implementation. This presentation explores the outcomes of two distinct strategies developed to recruit urban youth, ages 11-17, from Pittsburgh, PA for a study examining tobacco use counter-marketing media and describes the community partnership, the evolution of the recruitment methods, and factors that both facilitate and impede the recruitment process. Initial recruitment efforts utilized professionally-designed multimedia. Through a unique partnership among private, university and community entities, a second strategy was developed to involve underserved youth. Data are drawn from participant surveys and weekly recruitment logs. Preliminary data demonstrates that the recruitment strategies yielded demographically different youth. The majority of youth that responded to the multimedia campaign $(n=57)$ were Caucasian $(80 \%)$, while $100 \%$ of the youth recruited through the community partnership $(n=60)$ self-identified as African American. Factors associated with the characteristics of each recruitment method (e.g. retention rates), lessons learned, and implications for future research will be presented with specific attention paid to the importance of community partnerships in the recruitment of minority youth.

\section{INNOVATION AND ENTREPRENEURSHIP}

\section{P17-01 Urbanization, Building Pattern and Commercial Growth in Nigeria ; A Study of Ado- Ekiti Metropolis.}

Olu-Olu Olufayo, PhD (University of Ado- Ekiti, Nigeria.)

The location of some settlements and the intense commercial activities occasioned by this have seen to the rising status of some local communities to Urban cities. This Metamorphosis often appears sudden thereby catching the city dwellers unaware. The resultant effects amongst others, are that of migration and a general hyper-inflation, considered a necessary feature of Urbanization. However, a crippling development is being witnessed as commercial activities are being retarded due to a lack of structure (physical) needed for their growth. This paper therefore examines the building patterns characterised of these new urbanized areas and its influence on economic development. A well structured guestionnaire which was complemented with both the observational and in-depth interview were employed for the research. Findings revealed among others, the stark reality of poverty and a lack of a general planning policy on the part of government warranting the unnecessary hardship on the people. Recommendations were however made for improvement.

\section{P17-02 Stroke Care Bundle}

Petra Garnes; Judith Barnaby (St. Michael's Hospital, South East Stroke Network) The Stroke Care Bundle is a patient and family "package" designed to provide comprehensive support and education for the stroke survivor and their caregivers/ family members. The package consists of three main components for supporting stroke patient admitted to St. Michael's Hospital.

1. Welcome Package: This package is delivered to each patient by the Stroke Case Manager, during her initial visit with the patient and the family. The package consist 
of the booklet "Let's Talk About Stroke", a list of contact names and numbers of the stroke team, a contact name and number for the manager of the stroke unit and information regarding rehabilitation and community support services.

2. SMILES (Stroke Management in Lifestyle Education Session) for inpatients. The overall goal is to provide participants with general knowledge and awareness of best practice acute stroke care. The program specifically targets stroke survivors, friends and family during the acute care period. SMILES will provide an interdisciplinary approach to patient and family teaching about the causes of stroke, signs and symptoms, identification and management or risks.

3. Post-Discharge Telephone Support Services conducted by our stroke case manager facilitates the transition period from hospital to home by reinforcing discharge teaching and answering/clarifying questions that emerged once the patient was discharged from the acute care environment. There is a gap from discharge to their first appointment to be seen by a professional health care provider. This period can be a source of anxiety. Patients often experience fear uncertainty, regarding new regimens and the expected recovery process, which can be heightened on discharge home. It is also noted that one week post discharge can reveal social and health issues. Some studies, for example, Weaver et al, (2001) and Keeling et al. (1995) indicated that the use of a telephone intervention can be useful in addressing issues that occur on discharge.

\section{MEDICAL INFORMATICS IN CITIES}

\section{P18-01 Clinical Medical Ethics Issues}

Nirajan Ghimire (Nepal Academic Development and Community Health Academy) Background: Basic human rights are often denied to high-risk populations especially to people living with HIV/AIDS. This community based program was organized to determine the condition of clinical medical ethics in various hospitals of Nepal.

Methods: 100 medical students each selected from private and government medical colleges were asked to fill out a questionnaire with general questions and specific questions about the clinical medical ethics such as 1) if they would practice illegal medical abortions 2) if they would provide absolute health care to the HIV/ AIDS infected patients 3 ) if they would approach patients with one or the other communicable diseases and help them recover fully 4) if they would help in the treatment of a patient irrespective of the patient's financial status.

Results: The current study shows that $88 \%$ of the medical students would go by the medical ethics. They are aware of various medical ethics and are absolutely determined to help those who seek for medical assistance without any discrimination. According to the most of the patients are unaware about this side of medical practice.

Conclusions: The findings of the present study call for medical college based education programs to create awareness among the patients on the clinical medical ethics issues as well.

\section{P18-02 Building the Client-Clinic Relationship using Teen-Friendly Technology:} The CONTAC-U Project

Kathleen M. Cardona, DrPH; Cynthia Mobley, MD, MPH; Laurie Schwab Zabin, PhD (Johns Hopkins Bloomberg School of Public Health)

The CONTAC-U (CONnecting with Teens About Contraceptive Use) Project is a collaboration between Johns Hopkins Bloomberg School of Public Health and the 
Baltimore City Health Department. By employing innovative technological methods, this intervention aims to build the client-clinic relationship and enhance the family planning clinic's role in adolescent contraceptive method choice and continuation. Clients will choose from a variety of contact methods, including text messaging, email, IM, MySpace, and phone as means of contact with the clinic. Contacts will be scheduled, initiated, and recorded using a new web-based database designed for this project, enabling the clinic to provide regular, longitudinal follow-up. All female clients age $<20$ presenting to the Healthy Teens \& Young Adults Center in Baltimore City over 18 months will be invited to participate; project staff will provide individualized methods counseling and will contact each client at regular intervals beginning 2 weeks post-enrollment and then at least monthly to discuss issues such as side effects, method use, and appointment reminders. Outcome measures will include initiation and continued use of appropriate contraception, and unintended pregnancy rate. Overall, we hope to produce an easily replicable, technology based and adolescent-friendly means of continuing contact to enhance contraceptive protection among adolescents. 